\title{
Kuwaiti Parents' Knowledge of First-Aid Measures of Avulsion and Replantation of Teeth
}

\author{
Qumasha Al-Jame $^{a}$ Lars Andersson $^{b}$ Adel Al-Asfour ${ }^{b}$ \\ Departments of a Pediatric Dentistry, Specialist Dental Center, Amiri Hospital, Ministry of Health, and \\ ${ }^{b}$ Oral and Maxillofacial Surgery, Department of Surgical Sciences, Faculty of Dentistry, Kuwait University, Kuwait
}

\section{Key Words}

Tooth avulsion • Tooth replantation · Tooth exarticulation • Lay knowledge, parents

\begin{abstract}
Objective: The aim of this study was to assess the knowledge level of emergency measures for tooth avulsion among Kuwaiti parents. Subjects and Methods: Sixty-three parents completed an Arabic language questionnaire about their first-aid knowledge. The following fields of knowledge were assessed: general body injury treatment principles, tooth avulsion and replantation principles, avulsed permanent/ primary teeth, cleaning of an avulsed tooth before replantation, extra-alveolar time and storage media. For each category, a score ranging from 0 to 3 was possible. Results: Experience of first-aid information or training was seen in 12 (19\%) except for dental injuries, which had not been included in such first-aid information. Knowledge was demonstrated in 52 (82\%) about first aid of minor body injuries, yet the knowledge of how to manage avulsed teeth was poor, as 50-54 (79-86\%) parents had no knowledge of how to manage an avulsed tooth in the specific modes of treatment measured. There was no difference in knowledge between mothers and fathers, young or old, nor was knowledge greater in parents with an academic education. Conclusion:
\end{abstract}

First-aid knowledge in Kuwaiti parents is lacking for avulsion and replantation of teeth despite a high level of knowledge of how to manage simple body injuries. Knowledge of firstaid measures regarding avulsion and replantation of teeth should be increased by intervention programs.

Copyright $\odot 2007$ S. Karger AG, Basel

\section{Introduction}

Dental trauma occurs frequently in society, causing a burden for both individual and society [1-4], as costs for treatment after dental trauma are high [4-6]. The prognosis of many dental injuries is decided at the time and place of accident but can be improved if correct measures are taken [1, 7-13]. The most serious dental injury is avulsion (exarticulation) of a tooth [1]. The prognosis is related to the injury of the periodontal membrane during the time the tooth is out of its socket $[1,7-13]$.

Ideally, an avulsed tooth should be replanted in its socket as soon as possible to avoid further damage to the periodontal membrane $[1,7-13]$. Although primary teeth may also be avulsed, there is a risk of replanting them because this manipulation may result in injury to the underlying permanent tooth germ [1].

\section{KARGER}

Fax +4161306 1234

E-Mail karger@karger.ch

www.karger.com
(C) 2007 S. Karger AG, Basel

$1011-7571 / 07 / 0164-0274 \$ 23.50 / 0$

Accessible online at:

www.karger.com/mpp
Prof. Lars Andersson

Department of Surgical Sciences, Faculty of Dentistry, Kuwait University PO Box 24923

Safat 13110 (Kuwait)

Tel. +965 498 6712, Fax +965 532 6049, E-Mail lars.andersson@hsc.edu.kw 
Dry storage of the tooth will cause irreversible injury to the periodontal membrane, resulting in loss of the replanted tooth over time [7, 8, 13-17]. However, storing the tooth in water is not recommended because its osmolality is too low [18-20]. Wrapping the tooth in plastic wrap can prevent evaporation for at least $1 \mathrm{~h}$ [15], or the tooth may be stored in saline or a balanced salt solution $[7,16$, 18]. Storing the tooth in the patient's saliva is another alternative for shorter periods $[7,14,16]$. The use of specially composed cell culture media has been mentioned in the literature $[1,10,13]$, but such media are seldom accessible at the place of accident. Milk, however, which can usually be found in the vicinity of the place of accident, has a favorable osmolality and composition for the viability of periodontal ligament cells and therefore has been recommended for temporary storage of avulsed teeth before replantation $[18,20]$.

Knowledge of the important steps to take after an accident increases the success rate for the avulsed and replanted permanent tooth $[1,10,11,16]$. For this reason, it is important to educate the public about accidents involving tooth avulsion in children. Most studies on lay knowledge of tooth avulsion indicate that the level of knowledge is low [21-31]. In a recent study in Kuwait, it was shown that children have a low level of knowledge about avulsed teeth [31]. Although many of the children had received general first-aid information, dental injuries were not included [31].

Providing information is a way to increase knowledge of dental first aid. Parents can play an important role in improving the prognosis of avulsed permanent teeth of schoolchildren if they are informed about the first-aid steps to be taken at the time of an accident. Before planning information campaigns, it is important to assess the knowledge level of parents. As no previous study has been done in Kuwait to evaluate the knowledge of parents about emergency procedures for tooth avulsion, the purpose of this study was to assess the Kuwait parents' level of knowledge.

\section{Subjects and Methods}

Parents were asked to take part in an evaluation of knowledge about tooth avulsion and replantation. Participation in the study was voluntary and completely confidential, as names were not required on the questionnaires given to all parents who presented for dental treatment for their children either to the Pediatric Dental Unit, Amiri Dental Center, or a private practice in Kuwait City. The questionnaires were in the Arabic language, and parents completed them while waiting for their children's treatment. All
63 questionnaires given out were completed; no parent refused to take part in the study. The first part of the questionnaire consisted of general demographic data. In the second part, parents were asked if they had any training in first aid, and if so, whether dental emergencies had been included. Experience of previous trauma was also recorded.

Questions first assessed general knowledge and then more specialized knowledge. Parents were asked about their knowledge of emergency situations with emphasis on the following areas: (A) knowledge of trauma other than dental; (B) knowledge about teeth and avulsion; (C) special knowledge of tooth avulsion and replantation. Three to 5 questions were designed to assess parents' knowledge. A score ranging from 0 to 3 was given where $0=$ no knowledge, 1 = minor knowledge, 2 = good but incomplete and 3 = complete knowledge. In section $\mathrm{C}$, more exact knowledge was assessed in the following areas: (a) replantation of permanent teeth only; (b) methods of cleaning the tooth before replantation; (c) extra-alveolar time.

For details of all questions, a thorough description of the scoring method and design of the form, see Appendix and Andersson et al. [31]. Scores were calculated and descriptive statistics were used to describe and analyze the data. ANOVA was applied to test for significant differences between age, gender and parents' level of education. A significant difference was considered at $\mathrm{p}<0.05$.

\section{Results}

Sixty-three parents or guardians participated in this study. The mean age was $34.5 \pm 6.2$ years. Forty-one $(65 \%)$ were mothers, 21 (33\%) fathers and $1(2 \%)$ an adult closely related to the child. Fifty (79\%) of the parents had a university education after high school of 2 or more years.

\section{Information about First Aid}

Fifty-one (81\%) reported they had never received any information about first aid. Those who reported having received information described this as general information without any inclusion of first aid for dental injuries. Sixty $(95 \%)$ of the parents had not had any information about first aid for dental injuries. Three parents (5\%) recalled having received information about first aid for dental injuries.

\section{General Knowledge Variables}

Body Trauma. Eleven (18\%) parents had no knowledge about first-aid treatment of simple body injuries (score 0). Thirty-six (57\%) showed some information (score 1) and 15 (24\%) good information. One (2\%) showed complete knowledge.

Tooth and Avulsion in General. Nineteen (30\%) parents could not demonstrate any knowledge of tooth avulsion; 40 (64\%) had some knowledge, and 4 had good knowledge. No one had complete knowledge (score 3 ). 
Primary Teeth. Forty-four (70\%) did not have any knowledge about primary teeth and replantation; 16 (25\%) showed some knowledge (score 1), and 3 (5\%) showed good or complete knowledge (scores 2 and 3 ).

\section{Specific Treatment-Related Variables}

Tooth Cleaning. Fifty parents (79\%) did not have any knowledge of how to clean the tooth; 13 (21\%) showed some knowledge (score 1), and there were no parents with good or complete knowledge (scores 2 and 3).

Extra-Oral Storage Time. Fifty-five parents (87\%) did not know anything about extra-oral storage time; $6(10 \%)$ showed some knowledge (score 1); 1 (2\%) showed good knowledge (score 2), and another demonstrated complete knowledge (score 3).

Storage Method. Fifty-four (86\%) parents demonstrated lack of knowledge regarding storage method and medium; 9 (14\%) parents demonstrated minor knowledge (score 1), and no parents had good or complete knowledge (score 2 or 3 ).

Parent's Age, Gender and Educational Level. There was no significant difference in the level of knowledge between young $(<30$ years) and old parents, fathers and mothers or parents with an academic education after high school compared to those without postsecondary education.

\section{Discussion}

Questionnaires are good for screening provided they are carefully designed. For this study, a standardized questionnaire was used to check the level of knowledge. Questions were formulated in simple language and parents given an opportunity to make inquiries when the questionnaire was collected. Nonetheless, very few inquiries were made, indicating that the questions and design of the questionnaire were appropriate.

The method of using key questions for different knowledge areas has been successfully used [31], but no previous study has been recorded in the literature using such a scoring system for studying the level of knowledge for dental trauma. The advantage of using a system to score the level of knowledge is that knowledge levels for different categories can be measured and compared, providing an opportunity to optimize strategies for intervention for different categories. Furthermore, comparisons can be made over time, enabling researchers to follow developments after an intervention. In addition, scoring of knowledge also affords an opportunity to measure and compare the effects of different methods of intervention.

Within the limitations of the present study, the results indicate that parents have a low level of knowledge regarding tooth avulsion and replantation and procedures to follow in an emergency. This finding is in accordance with two other studies of parental knowledge performed in Nigeria [28] and Singapore [29]. An absence of knowledge will result in avulsed teeth not being replanted or stored in a nonphysiological medium prior to replantation, which will severely affect the prognosis of the tooth. This is unfortunate because, with simple measures, most avulsed teeth can be successfully replanted with a good prognosis. Since parents were well educated, many of them with university degrees, it is apparent that the level of education had no influence on the knowledge of tooth avulsion. This is probably because very little or no information about tooth avulsion and replantation has been given to Kuwaiti parents. Parents were more knowledgeable about how to treat simple emergency injuries to other parts of the body, probably because there has been some basic education. Considering that dental injuries occur frequently, it is remarkable that they are not included in general first-aid information. This lack of instruction is not limited to Kuwait but has been reported in other countries $[21,22,27]$. It would be beneficial if instruction in how to manage dental injuries would be more widespread in society. Many teeth could be saved and the unnecessary suffering from a lost permanent tooth in early childhood could be avoided.

Loss of a permanent tooth results in severe functional, esthetic and psychologically negative consequences. In young children, permanent replacement of lost teeth with implants and bridge therapy is not recommended because of the risk of interfering with the development of the jaw while the children are still growing [1]. For this reason, these children have to wait for their final treatment until growth has been completed, resulting in temporary, often removable dentures in a psychologically sensitive period of life. Moreover, losing and replacing a permanent front tooth results in high costs for the family and society $[1,2,5]$. The annual incidence of dental injuries has been reported to be 13/1,000 in the permanent dentition among children and adolescents resulting in a prevalence of $30-40 \%$ in the age of $16-18$ years [1, $3-5]$. Avulsion injuries comprise $2 \%$ of all dental injuries [2]. It is estimated that around 100-150 children in $\mathrm{Ku}-$ wait will suffer from new avulsion injuries of permanent teeth each year. Many of these teeth could be replanted and saved if the children and parents knew what proce- 
dures to follow after an avulsion injury. A recent study showed that the knowledge level of children was low so parents are an important group since many dental injuries occur when the child is in the home environment [31]. An avulsed permanent tooth can be replanted with successful healing and the tooth retained for life. The prognosis of healing depends on appropriate emergency management immediately after the avulsion trauma [1, 7-11]. A number of experimental and clinical studies have yielded extensive knowledge on the impact of the injury, the relationship between the measures taken and the prognosis of healing, as well as healing of the tissues [1-20, 32-33]. Nevertheless, the prognosis is still largely determined in the first $15 \mathrm{~min}$ after trauma has occurred [9]. By acting quickly and effectively, an avulsed tooth can be successfully replanted and retained in most cases. By increasing knowledge of how avulsed teeth are to be dealt with at the site of the accident, the risk of incurring future negative consequences is minimized. As a result of more teeth being saved, there will be no need for replacement by bridge or implant treatment and these costs of treatment will be reduced for the individual and Kuwaiti society.
Increasing the knowledge of parents on the emergency management of knocked-out teeth is desirable by creating suitable and directed educational programs. There are various ways to achieve this goal. These programs could also include teachers, sports leaders, coaches, nurses, receptionists in emergency centers and even physicians. There are various ways to achieve this goal.

\section{Conclusion}

First-aid knowledge in Kuwaiti parents is lacking for avulsion and replantation of teeth despite a high level of knowledge of how to manage simple body injuries. Knowledge of first-aid measures regarding avulsion and replantation of teeth should be increased by intervention programs.

\section{Acknowledgement}

This study was financed by Kuwait University Research Grant DS 01/05.

\section{Appendix}

Has your child ever damaged a tooth so that it was loose or cracked?

Yes/No

If yes, what kind of tooth injury have you experienced in the past?

Previous training in emergencies

Did you ever have any information or training about what to do when you hurt yourself (first aid)? Yes/No

What type of information or training was that?

Was information of tooth injuries included?

A General knowledge of emergency treatment of trauma to some other parts of the body

1 What would you do if you burnt the tip of your finger on a flame or in hot water?

2 What would you do if you cut your finger and it began to bleed?

3 What would you do if you had a nosebleed?

4 What would you do if you fell on the street and scraped some of the skin from your knee and the abrasion were dirty?

To achieve a score of 3 , the parent has to demonstrate knowledge of each of the following principles:

- Know that a burnt finger should immediately be put in a cool environment such as in contact with ice, cool water or oil-containing paste

- A cut finger should be treated by compression (e.g. gauze, handkerchief) until the bleeding has stopped. A bandage or strip should be applied

- A nosebleed should be treated by compression (finger pinching) of the lower part of the nose or packing of the nose with gauze

- Clean the abrasion injury by rinsing (in water, saline or antiseptic solution) and removing all traces of dirt

To achieve a score of 2, knowledge of at least 3 of the above points has to be demonstrated

To achieve a score of 1 , knowledge of at least 2 of the above principles has to be demonstrated

B General knowledge of tooth structure and avulsion

1 Do you know how the tooth is normally kept in its position in the jaw so that it will not fall out when you chew?

2 Do you think a tooth can be completely knocked out? Yes/No

3 If a tooth is knocked out by accident, do you think it can be put back so that you can chew Yes/No and smile with it just like you did before the accident?

To achieve a full score of 3 , the parent needs to demonstrate knowledge of the 3 principles below:

- Know that the tooth is attached to the bone by fibers

- Know that a tooth can be knocked out totally

- Know that an avulsed tooth can be replanted, heal and function again

To achieve a score of 2, knowledge of 2 of the above principles has to be demonstrated

To achieve a score of 1, some knowledge has to be demonstrated but less than 2 points 
C Special knowledge of avulsion and replantation

In this part of the interview questions are presented in four important fields of knowledge: replantation of primary teeth, how to clean a tooth before replantation, extra-alveolar time and storage method and medium

a Replantation of primary teeth

1 Do you think primary (baby, temporary) teeth should be put back in after they have been knocked out?

2 If the answer is no, why not?

3 Do you think permanent (the teeth you will have for the rest of your life) teeth should be put back after they have been knocked out?

To achieve a full score of 3 , the parent has to know all the following information:

- Primary teeth should not be replanted

- The reason for not replanting a primary tooth is the risk of injury to the underlying permanent tooth germ

- Permanent teeth should be replanted whenever possible

To achieve a score of 2, knowledge of 2 of the above principles has to be demonstrated

To achieve a score of 1,1 of the above principles has to be demonstrated

$b$ How to clean the tooth before replantation

1 If the tooth has fallen on the ground and is dirty, what will you do?

2 If you have to clean the tooth first, how do you clean it?

3 Do you clean the tooth also if it is not dirty?

4 How do you hold it while washing it?

5 Is it important to rub away all the dirt?

6 What do you do if you cannot rinse away all dirt?

To achieve a full score of 3 , the parent has to know all the following information:

- The dirty tooth should be rinsed in water (not in antiseptic solution)

- The tooth should be held by its crown, and touching the root surface should be avoided

- Rubbing of the root should be avoided

- Dirty teeth should be transported in a storage medium (not water) on the way to a dentist

To achieve a score of 2, knowledge of 2 of the above principles has to be demonstrated

To achieve a score of 1,1 of the above principles has to be demonstrated

c Extra-alveolar time

1 When should the tooth be put back in if it had been knocked out of the mouth? (Choose the best alternative)

- Immediately

- As soon as the bleeding has stopped

- During the first hour

- Within the first $6 \mathrm{~h}$

- Within the same day

- When visiting the dentist

2 Why?

3 Do you think a tooth can be out of your mouth for a longer time if stored in another way than dry storage?

To achieve a full score of 3 , the child has to know all of the following information:

- A tooth should be replanted as soon as possible

- The reason is that the root cells (or periodontal membrane) will be injured by dry storage

- Teeth can be stored for longer periods if put in a suitable storage medium

To achieve a score of 2, knowledge of 2 of the above principles has to be demonstrated

To achieve a score of 1,1 of the above principles has to be demonstrated

d Storage method and medium

1 What do you do if you cannot (or chose not to) put back the tooth?

2 How do you keep the tooth on the way to the dentist?

3 Have you heard about any other way of storing a tooth that has been knocked out before it is put back in its socket?

4 Mark desirable and undesirable ways of storing a tooth that has been knocked out while you are on your way to the dentist (a list of suggestions is shown below)

- Wrap the tooth in paper

- Wrap the tooth in a handkerchief

- Wrap the tooth in gauze or cotton

- Wrap the tooth in cellophane

- Put the tooth in water

- Put the tooth in a disinfecting solution

- Put the tooth in ice water

- Place the tooth in the child's mouth

- Place the tooth in the child's hand

- Put the tooth in milk

- Put the tooth in fruit juice

- Put the tooth in saline solution

- Put the tooth in Coca Cola

To achieve a full score of 3 , the parent has to know all of the following information:

- The tooth can be stored if it cannot be replanted

- The tooth must not be stored dry

- The tooth must not be stored in water

- The correct answer of at least 12 of 13 questions in the above question 4

To achieve a score of 2, knowledge of at least 2 of questions 1-3 and at least 10 of 13 questions in question 4 needs to be demonstrated

To achieve a score of 1 , some knowledge has to be demonstrated but less than 3 of the above principles 


\section{References}

1 Andreasen JO, Andreasen F, Andersson L (eds): Textbook and Color Atlas of Traumatic Injuries to the Teeth. Oxford, Blackwell Munksgaard, 2006, vol 4.

$\checkmark 2$ Glendor U, Halling A, Andersson L, EilertPeterson E: Incidence of traumatic tooth injuries in children and adolescents in the county of Västmanland, Sweden. Swed Dent J 1996;20:15-28.

$>3$ Petersson EE, Andersson L, Sörensen S: Traumatic oral vs non-oral injuries: an epidemiological study during one year in a Swedish county. Swed Dent J 1997;21:5568.

4 Borum MK, Andreasen JO: Therapeutic and economic implications of traumatic dental injuries in Denmark: an estimate based on 7,549 patients treated at a major trauma centre. Int J Paediatr Dent 2001;11:249-258.

5 Glendor U: On dental trauma in children and adolescents: incidence, risk, treatment, time and costs. Swed Dent J 2000;40 (suppl):1-52

-6 Sane J: Comparison of maxillofacial and dental injuries in four contact team sports: American football, bandy, basketball and handball. Am J Sports Med 1988;16:647651.

7 Andreasen JO: The effect of extra-alveolar storage and storage media upon periodontal and pulpal healing after replantation of mature permanent incisors in monkeys. Int J Oral Surg 1981;10:43-53.

$>8$ Andersson L, Bodin I, Sörensen S: Progression of root resorption following replantation of human teeth after extended extraoral storage. Endod Dent Traumatol 1989;5: 38-47.

$\checkmark 9$ Andersson L, Bodin I: Avulsed human teeth replanted within 15 minutes - A long-term clinical follow-up study. Endod Dent Traumatol 1990;6:37-42

10 Trope M: Clinical management of the avulsed tooth. Dent Clin North Am 1995;39: 93-112.

11 Barrett EJ, Kenny DJ: Avulsed permanent teeth: a review of the literature and treatment guidelines. Endod Dent Traumatol 1997;13: 153-163.
$>12$ Chappuis V, von Arx T: Replantation of 45 avulsed permanent teeth: a 1-year follow up study. Dent Traumatol 2005;21:289-296.

13 Pohl Y, Filippi A, Kirschner H: Results after replantation of avulsed permanent teeth. Parts I-III. Dent Traumatol 2005;21:80110.

14 Cvek M, Granath L-E, Hollender L: Treatment of non vital permanent incisors with calcium hydroxide. III. Variation of occurrence of ankylosis of reimplanted teeth with duration of extra-alveolar period and storage environment. Odont Revy 1974;25:4356.

5 Blomlöf L, Andersson L, Lindskog, Hedström K-G, Hammarström L: Periodontal healing of replanted monkey teeth prevented from drying. Acta Odontol Scand 1983;41 117-123.

16 Andreasen JO, Borum MK, Jacobsen HL, Andreasen FM: Replantation of 400 avulsed permanent incisors. 4. Factors related to periodontal ligament healing. Endod Dent Traumatol 1995;11:76-89.

17 Heimdal A, von Konow L, Lundquist G: Replantation of avulsed teeth after long extraalveolar periods. Int J Oral Surg 1983;12: 413-417.

18 Blomlöf L: Milk and saliva as possible storage media for traumatically exarticulated teeth prior to replantation (thesis). Swed Dent J Suppl 1981;8:1-26.

19 Sigalas E, Regan JD, Kramer PR, Witherspoon DE, Opperman LA: Survival of human periodontal ligament cells in media proposed for transport of avulsed teeth. Dent Traumatol 2004;20:21-28.

-20 Blomlöf L, Lindskog S, Andersson L, Hedström K-G, Hammarström L: Storage of experimentally avulsed teeth in milk prior to replantation. J Dent Res 1983;62:912-916.

$\checkmark 21$ Hamilton FA, Hill FJ, Mackie IC: Investigation of lay knowledge of the management of avulsed permanent incisors. Endod Dent Traumatol 1997;13:19-23.

22 Holan G, Shmueli Y: Knowledge of physicians in hospital emergency rooms in Israel on their role in cases of avulsion of permanent incisors. Int J Paediatr Dent 2003;13: $13-19$.
23 Newman L, Crawford PJM: Dental injuries: first aid knowledge of Southampton teachers of physical education. Endod Dent Traumatol 1991;7:255-258.

24 Pacheco LF, Filho PFG, Letra A, Menezes R,Villoria GEM, Ferreira SM: Evaluation of the knowledge of the treatment of avulsions in elementary school teachers in Rio de Janeiro, Brazil. Dent Traumatol 2003;19:7678.

25 Raphael SL, Gregory PJ: Parental awareness of the emergency management of avulsed teeth in children. Aust Dent J 1990;35:130 133.

26 Sae-Lim V, Lim LP: Dental trauma management awareness of Singapore pre-school teachers. Dent Traumatol 2001;17:71-76.

27 Stokes AN, Anderson HK, Cowan TM: Lay and professional knowledge of methods for emergency management of avulsed teeth. Endod Dent Traumatol 1992;8:160-162.

28 Sanu OO, Utomi IL: Parenteral awareness of emergency management of avulsion of permanent teeth of children in Lagos, Nigeria. Niger Postgrad Med J 2005;12:115-120.

29 Sae-Lim V, Chulaluk K, Lim LP: Patient and parental awareness of the importance of immediate management of traumatized teeth. Endod Dent Traumatol 1999;15:37-41.

30 Blakytny C, Surbuts C, Thomas A, Hunter ML: Avulsed permanent incisors: knowledge and attitudes of primary school teachers with regard to emergency management. Int J Pediatr Dent 2001;11:327-332.

-31 Andersson L, Al-Asfour A, Al-Jame Q: Knowledge of first aid measures of avulsion and replantation of teeth: an interview study of 221 Kuwaiti school children. Dent Traumatol 2006;22:57-65.

32 Schwartz O, Andreasen FM, Andreasen J: Effects of temperature, storage time and media on periodontal and pulpal healing after replantation of incisors in monkeys. Dent Traumatol 2002:18:190-195.

-33 Oikarinen K, Andreasen JO, Andreasen FM: Rigidity of various fixation methods used as dental splints. Endod Dent Traumatol 1992; 8:113-119. 